\title{
Music in the Digital Age: Downloading, Streaming and Digital Lending
}

\author{
James Mason, University of Toronto \\ Jared Wiercinski, Concordia University
}

\section{Introduction}

The ways in which we listen to music, and the places we look to find it, have changed radically in the last thirty years. In 1980, Philips and Sony proposed the Red Book standard for Compact Discs (CDs), ${ }^{1}$ with a little help from Beethoven. ${ }^{2}$ Although it was not the first storage medium for digital audio, the introduction of the CD signaled that the world of digital music was about to go mainstream. The technology behind communications devices such as telephones, radios, and personal computers continued to evolve, and before long, the foundation for the Internet was firmly in place. This multifaceted and complex "global system of interconnected computer networks" ${ }^{3}$ was about to revolutionize the distribution of sound recordings. As Leiner says, "The Internet is at once a world-wide broadcasting capability, a mechanism for information dissemination, and a medium for collaboration and interaction between individuals and their computers without regard for geographic location." ${ }^{4}$

Only fifteen years after the introduction of the Red Book, music was being distributed over the Internet. RealNetworks' RealAudio Player, for example, was released in April 1995, and was one of the first media players capable of streaming media over the Internet. ${ }^{5}$ Now, recorded music is more accessible than ever before. We enjoy unprecedented access to music through a variety of means, including both web access and via mobile devices such as smartphones, the iPod touch

\footnotetext{
1 British Broadcasting Corporation (BBC) News, "How the CD Was Developed," http://news.bbc.co.uk/2/hi/technology/6950933.stm (accessed March 16, 2010).

2 “Philips' plan for a CD with a $11.5 \mathrm{~cm}$ diameter had to be changed when Sony insisted that a disc must hold all of Beethoven's 9th Symphony. The longest recording of the symphony in record label Polygram's archive was 74 minutes and so the CD size was increased to $12 \mathrm{~cm}$ diameter to accommodate the extra data."

British Broadcasting Corporation (BBC) News, "How the CD Was Developed," http://news.bbc.co.uk/2/hi/technology/6950933.stm (accessed March 16, 2010).

3 “Internet," Wikipedia, http://en.wikipedia.org/wiki/Internet (accessed March 16, 2010).

4 Barry M. Leiner et al., "A Brief History of the Internet," Internet Society, http://www. isoc.org/internet/history/brief.shtml (accessed March 16, 2010).

5 “About Us," RealNetworks, http://www.realnetworks.com/about-us/index.aspx (accessed March 16, 2010).
}

(C) 2010 The authors and the Canadian Association of Music Libraries, Archives, and Documentation Centres / Les auteurs et l'Association canadienne des bibliothèques, archives et centres de documentation musicaux. 
and other portable music players. There is a tremendous amount of music freely available on the web, and through public institutions such as libraries; there is also a vast amount offered via subscription or paid services.

Things are changing so quickly that regular stock-taking is essential, in order to ensure that we are aware of the many different places to find music. To this end we will describe and evaluate three different methods of accessing sound recordings online, providing examples along the way. We hope that this information will be helpful to librarians in two ways: first, to provide some assistance to librarians who are frequently required to help their users locate sound recordings; and second, to help librarians to better understand the wide array of options that tech-savvy users now have at their disposal for listening to music - options that will in some cases serve as direct competition to library services.

\section{Downloading audio}

\section{Overview}

Downloading involves transferring an entire audio file from one computer to another via the Internet. Downloaded files are accessible off-line and can be transferred again to other computers or devices; they can also be edited or modified using digital audio editing software. During the late 1980s and early 1990s, downloading was the only viable option for distributing music over the Internet; existing technologies were insufficient to support other methods of distribution (e.g., streaming technologies). ${ }^{6}$

At the time, music-playing software allowed listeners to play physical CDs and, before long, to also transfer the audio files from the CD to the listener's hard drive (also known as "ripping"). The newly encoded files could also be played with the same music-playing software, which employed a user interface that was closely modeled after those of their physical counterparts (i.e., stand-alone CD players). Though downloading files from the Internet was possible, ripping CDs was the primary method that people used to add music to their computers. Given this model - downloading or ripping audio files to a personal computer, and then playing them in the software of your choice - the user's listening experience was more or less self-determined, and largely out of the control of any particular music distributor. As a result, when it came to playing digital music, the user experience could vary drastically from one listener to the next.

As people started to populate their hard drives with music ripped from CDs, networks of users began to share these saved files - mainly through Internet Relay Chat (IRC) networks and by using the file-transfer capabilities of the IRC software. ${ }^{7}$ As a result, downloading audio really took off as a means of acquiring new music. Online music stores were not yet commercially viable, though, given the absence of the technologies required for administering online payments. ${ }^{8}$

\footnotetext{
${ }^{6}$ David Austerberry, The Technology of Video and Audio Streaming (Burlington: Focal Press, 2005), 133.

7 “History," Filesharing.com: The Ultimate File Sharing Resource, http://www.filesharing.com/history/ (accessed March 17, 2010).

8 “History of Ecommerce," Ecommerce-Land, http://www.ecommerce-land.com/history_ecommerce.html (accessed March 17, 2010).
} 
Despite their promise, however, IRC technologies proved to be difficult to use for inexperienced users. There was also a degree of risk involved. First, there was no central database that users could connect to, and download files from. Successfully trading files, then, required the time to develop relationships with liked-minded users in order to establish reliable file sharing networks. Second, acquiring files from IRC networks meant running the risk of downloading a virus, a problem which remains to this day. Furthermore, downloading files in this fashion often involved breaking copyright laws. ${ }^{9}$

Then, in June 1999, Shawn Fanning launched Napster, with its user-friendly interface. A huge community responded, and the game of music distribution changed significantly. Although Napster did not last long - it shut down its network in July 2001 in order to comply with a courtordered injunction $^{10}$ - it set the stage for a massive proliferation of peer-to-peer file sharing networks.

Since Napster, the distribution of online music has undergone a process of evolution: user interfaces and online payment technologies continue to improve, while more and more music becomes available online. Selling music online - music which can easily be downloaded to a listener's computer and portable listening devices - has become a very profitable industry.

\section{Advantages and disadvantages}

The advantages to downloading audio files include issues of access and sound quality, as well as the ability to transfer and edit files. When you download files you own them, or at least have control over whether or not you want to keep them or delete them. This is not always true with other methods, like streaming audio from web sites, for example, where you rely on a content provider to continue to provide access to the music. Further, when the files are free of digital locks, i.e., digital rights management (DRM) technology, you can transfer the files to other computers or music-playing devices, and listen to them anytime - no Internet connection required. Downloaded audio files, on the average, also tend to have better sound quality compared to streaming audio, which is subject to bandwidth limitations. Online music stores and archival sites - such as Beatport and the Internet Archive, for example - may offer lossless sound quality downloads, whereas streaming audio sites typically use compressed, lossy quality files. You can also manipulate, edit, or remix downloaded sound files, something which is often necessary for DJs, sound artists, and musicians in general - again, with the caveat that the files will need to be DRM-free.

There are some negative aspects to using downloaded audio files: these include discovery and cost. If you exclusively (or primarily) listen to music that you have downloaded, you may be limited in your ability to discover new music. No matter how much memory your computer or portable music player holds, sooner or later you will run into the limitations of your own personal collection. Streaming an Internet radio station, on the other hand, offers the possibility

\footnotetext{
9 Marc Fetscherin, "Importance of Cultural and Risk Aspects in Music Piracy: A Cross-National Comparison Among University Students," J ournal of Electronic Commerce Research 10, no. 1 (2009): 45-46, http://www.csulb.edu/journals/jecr/issues/20091/Paper4.pdf (accessed March 17, 2010). 
of serendipity. It offers the chance to discover new music, often without the effort or costs associated with downloading purchased music.

\section{Examples}

\section{1. iTunes (http://www.apple.com/itunes/)}

ITunes is the most popular and widely-used commercial music download service available today. With iTunes, Apple offers access to digital music in a user-friendly interface. The success of iTunes is likely due to their business model, which has prioritized a high degree of integration between their iPod music players, the iTunes store, and the iTunes digital media software. This integration adds up to a very streamlined service which can make purchasing and listening to music both simple and enjoyable.

Originally, iTunes offered tracks that featured DRM technology, which limited the use of downloaded tracks to a certain number of computers, and restricted playing of the tracks to an iPod that was linked to the computer used to download the audio file. This could be frustrating from a user-perspective and opened up several questions about long-term access to purchased music. It wasn't until Amazon offered DRM-free MP3 files that Apple removed the digital locks from their files.

Apple may be planning to expand their iTunes service beyond offering digital music for download. Likely due to the success of streaming music services such as Lala (which Apple recently purchased for \$85 million), or due to increasing hype around "cloud computing," Apple is thought to be considering the option of allowing users to stream their purchased music from any computer over the Internet. ${ }^{11}$ This would provide expanded access to your personal collection, since it would not be tethered to any particular computer or portable device.

\section{2. eMusic (http://www.emusic.com/)}

Right from the start, eMusic adopted a different approach from iTunes, its main competitor, in that none of its tracks included DRM technology of any sort. All tracks were high quality MP3s, a DRM-free format. Once purchased, tracks could be copied or transferred to any number of computers or devices, or shared with others. But as a result of its DRM-free policy, eMusic was only able to secure licenses for content from independent labels. ${ }^{12}$ Now, however, some major labels have decided to allow eMusic to sell their content.

EMusic's business plan also differs from iTunes in that it operates as a subscription service. Plans currently range from 24 tracks per month for \$11.99 to 50 tracks for \$20.79. EMusic requires "download manager" software to be downloaded and installed on your

\footnotetext{
11 Ethan Smith and Yukari I watani Kane, "Apple Plots Reboot of iTunes for Web," Wall Street J ournal, December 11, 2009, http://online.wsj.com/article/SB126040631831584643.html (accessed March 17, 2009).

12 Nate Anderson, "Making Money Selling Music Without DRM: The Rise of eMusic," Ars Technica, http://arstechnica.com/gadgets/news/2006/05/emusic.ars (accessed March 17, 2010).
} 
computer. This software manages downloaded tracks and can automatically add them to folders of the user's choice, including the ability to add them directly into iTunes libraries.

\section{Napster (http://www.napster.ca/)}

The Napster of today, unlike its notorious predecessor, is a fully legal commercial retailer of downloadable music. Napster offers access to millions of songs on a subscription basis. Subscriptions, or "memberships,” start at \$9.99 a month. They offer two different options for downloading music. As a member you are entitled to an unlimited number of downloads, which you can keep and use as long as you maintain a membership; therefore, the tracks you download are only "leased" in a sense, and not owned. The second method involves paying an additional fee of $\$ 0.99$ per track, above the cost of membership. Files downloaded under this option are yours to keep, subscription or not.

\section{Amazon (http://www.amazon.com/)}

Amazon is a relatively new player in the music download business. Their MP3 downloads are currently not available in Canada, though there has been talk of this changing. ${ }^{13}$ One distinguishing characteristic of Amazon's service, one which has been greeted with considerable optimism, is that they offer content from both independent and major labels, all without DRM technology. ${ }^{14}$

Amazon offers millions of tracks for sale with a price range centering around \$0.89-\$0.99 per track. Special software is required to manage the download process. Like eMusic, this software can deposit the tracks where the user likes, including into an iTunes Library so that the tracks can be easily transferred to an iPod device.

\section{Others:}

- ClassicsOnline (http://www.classicsonline.com/)

- Beatport (https://www.beatport.com/)

- Traxsource (http://www.traxsource.com/)

- BravoMaestro (http://www.bravomaestro.com/)

\section{Streaming audio}

\section{Overview}

At the end of the 1990s several stars aligned: bandwidth capacities increased, as did access to Internet networks; standard protocols such as Transmission Control Protocol / Internet Protocol

\footnotetext{
13 Roberto Rocha, "Amazon MP3 Store: Global Rollout Promised, Not Delivered," The Gazette, December 19, 2008, http://communities.canada.com/montrealgazette/blogs/tech/archive/2008/12/19/amazon-mp3-store-globalrollout-promised-not-delivered.aspx (accessed March 16, 2010).

14 Joshua Topolsky, "Amazon Launches DRM-free 'Amazon MP3' Music Downloads," Engadget, http://www.engadget.com/2007/09/25/amazon-launches-drm-free-amazon-mp3-music-downloads (accessed March 15, 2010).
} 
(TCP/IP) emerged, alongside the development of HyperText Markup Language (HTML); the Internet was also becoming increasingly commercialized. These various factors combined to make streaming media a viable option. ${ }^{15}$ Furthermore, advances in home computing, especially with regards to increases in CPU power, meant that users could now stream audio files, largely without the interruptions or delays associated with network problems and long buffering times.

The term "streaming" can refer to two different methods of delivering audio over the Internet. One type is more correctly referred to as "progressive download," as the file is actually being downloaded to a temporary location on your computer. This leads to "buffering" while the computer waits for enough content to be saved before it can start playing. Progressive downloading, which is also referred to as "progressive streaming" or "HTTP streaming," is less expensive than its alternative, which is often referred to as "true streaming." Although progressive downloading is often sufficient for modest traffic, there can be drawbacks. First, since progressive downloading necessarily involves streaming a pre-existing file, this method is not suitable for live broadcasting (e.g., of a live music performance). Second, since progressive downloading uses linear buffering (i.e., the file is downloaded starting at the beginning of the file), jumping around from one point in the audio file to another can involve delays, especially with larger files. ${ }^{16}$ Despite these drawbacks progressive downloading technology is very popular, and numerous music and video streaming sites make use of it, including large sites such as YouTube, Vimeo, and MySpace.

True streaming requires proper streaming-server technology and the utilization of appropriate protocols, such as Real-time Streaming Protocol (RTSP), amongst others. It also involves transferring and buffering small amounts of a file at a time. On the user side, the file plays as it is received, and the user can jump around to different locations in the file, often with few or no delays. From the user side, though, there is often not much difference between progressive downloading and true streaming. There is, however, a crucial difference in these technologies: with true streaming the file is only transferred and viewed in small portions; at no time is the entire file ever transferred from the streaming server to the user's computer. And unlike progressive downloading, true streaming allows for the possibility of live broadcasting.

\section{Advantages and Disadvantages}

One of the main advantages of using web sites that feature streaming audio technology is that they open up access to a vast amount of content, music that you may not have available in your own personal collection. In effect, it allows you to play music that is stored on another computer or network, which makes it possible to discover music that you would otherwise have no way of accessing.

There are also several disadvantages. In a sense, streaming can be very inefficient. For example, when a user streams the same content repeatedly (e.g., a favourite song) they are using more bandwidth than they would have if they had simply downloaded the song once. From a

\footnotetext{
15 Martin Campbell-Kellyand William Aspray, Computer: a History of the Information Machine (Boulder: Westview Press, 2004), 274-275.

16 "Streaming Video Servers," Media College, http://www.mediacollege.com/video/streaming/server.html (accessed March 16, 2010).
} 
bandwidth perspective, then, streaming a file once or downloading a file are equivalent, assuming the two methods involve files of the same sound quality. While this may not be much of an issue when listening from a home or office computer where bandwidth prices are relatively inexpensive or free, it can make a significant difference in a mobile context where the price of bandwidth tends to be much more expensive. There are other drawbacks as well. Due to the complexities inherent in streaming technologies, technical problems can (and often do) creep up from time to time. This can translate into the music stopping mid-song, which makes for a frustrating listening experience. Further, because of bandwidth issues, music delivered by streaming audio technologies tends to be of lower sound quality than downloaded music, at least on the average. And finally, streaming audio requires a reliable Internet connection, something that is not always possible depending on your location (e.g., while in the subway or when outside of the city), mobile device, or financial situation.

\section{Examples: listen-on-demand services}

Music-on-demand style sites allow the user to choose a track and to play it right away.

\section{Grooveshark (http://listen.grooveshark.com/)}

Grooveshark is a browser-based service hosting one of the largest collections of music available on the Internet. Currently 22 million tracks are available for streaming. Grooveshark is adsupported, but the option to remove ads is available for a fee of \$3 per month. Grooveshark also allows you to upload tracks from your personal collection, which can then be streamed. This gives users the option of listening to their music from almost anywhere, including mobile devices, provided that they have an Internet connection. Grooveshark allows users to create playlists, to share tracks (i.e., Grooveshark generates a link that can be emailed to others and can be played right in their email client), and to purchase tracks through either Amazon or iTunes. Grooveshark also offers a "radio" feature.

\section{Spotify (http://www.spotify.com/int/)}

Spotify is another music service which offers a large amount of streaming content. At the moment, Spotify has 5.4 million tracks available. However, the service is currently available only in France. Spotify is a subscription service, requiring software to be downloaded. Spotify puts an emphasis on the social aspect of their service. Tracks and playlists can be shared, and playlists can be created communally. Mobile options are supported, as is an "off-line" mode this helps to ensure that your music is available whenever you need it. Biographies and suggestion lists are also offered, which contribute to the user experience. Spotify also offers a "radio" feature.

\section{3. we7 (http://www.we7.com/\#/)}

We7 is an ad-supported streaming music service that uses audio commercials. Currently we7 hosts over 3 million tracks. As with other, similar services, sharing is a prominent feature. Downloading and an ad-free option are both available for a fee. There is no software required for downloading as it is a browser-based service. 


\section{Lala (http://www.lala.com/)}

Lala is another browser-based service hosting over 8 million tracks to be streamed. Each streaming track must be purchased at a cost of $\$ 0.10$ per track. These tracks are referred to as "web songs." Although Lala is not currently available in Canada, this may change depending on new licensing arrangements with major labels. That said, much is likely to change with Lala as they have just recently been purchased by Apple. ${ }^{17}$ It is certainly possible that their technology will soon be incorporated into the iTunes platform.

Others:

- Deezer (http://www.deezer.com/en/)

- YouTube Disco (http://www.youtube.com/disco)

- thesixtyone (http://www.thesixtyone.com/)

- SoundCloud (http://soundcloud.com/)

- CitySounds.fm (http://citysounds.fm/)

- Naxos Music Library (http://www.naxosmusiclibrary.com)

- DRAM (http://www.dramonline.org/)

- Classical Music Library (http://www.alexanderstreetpress.com/products/clmu.htm)

- Naxos Music Library Jazz (http://www.naxosmusiclibrary.com/jazz/)

- Jazz Music Library (http://www.alexanderstreetpress.com/products/jazz.htm)

- Smithsonian Global Sound for Libraries (http://www.alexanderstreetpress.com/products/glmu.htm)

\section{Examples: internet radio style services}

Internet radio style sites typically allow the user to select a particular "station" to listen to (which is often based on a particular artist or genre), without allowing for the full control provided by listen-on-demand services.

\section{Last.fm (http://www.last.fm/)}

With Last.fm your user profile is enriched by every track you play. In a way, it "gets to know you" as you use the service. The web page states: "When you recommend some music to a friend, or you tag it, or you write about it - even just listening to it - you shift the song's importance on the site." 18

To use Last.fm's browser-based service you need to sign up for a free account, although the radio-streaming service costs around 6 dollars a month on a subscription basis. To start, you enter search terms, such as a song title or artist name, into a search box. Last.fm then generates a playlist for you based on a combination of your search criteria and your past listening habits.

\footnotetext{
17 John Timmer, "Apple Buys Music Streamer Lala, But What's It Getting?" Ars Technica, http://arstechnica.com/apple/news/2009/12/apple-buys-music-streamer-lala-but-whats-it-getting.ars (accessed March 16, 2010).

18 “About Last.fm," Last.fm, http://www.last.fm/about (accessed March 16, 2010).
} 
You can skip tracks, if you want, but cannot replay tracks once they have already been played. Playlists, biographies and recommendations (based on your own use, and on that of users with similar musical tastes) are interesting aspects of the service.

\section{Slacker (http://www.slacker.com/)}

Once they have registered for an account, Slacker users have the ability to listen to a genre-based station, to customize a station, or to create a station of their own. The service is free for 30 days, at which point you are required to upgrade to a "pro" account, which costs from \$3.99 to \$4.99 a month. With Slacker, a user can cache a station to a mobile device for offline listening. Slacker also offers song lyrics, biographies, and reviews.

\section{Others:}

- Musicovery (http://www.musicovery.com/)

- Radiolicious (http://www.radiolicious.fm/)

- Pandora (http://www.pandora.com)

- iheartradio (http://www.iheartradio.com/)

Examples: streaming audio as a value-added option

Various organizations, institutions and broadcasters offer streaming audio in order to complement other, more traditional forms of distribution.

\section{Canadian Music Centre (http://www.musiccentre.ca/home.cfm)}

After creating an account, users can listen to thousands of recordings of music by Canadian composers, all free of charge and completely ad-free.

\section{CBC Radio 2 (http://www.cbc.ca/radio2/)}

In addition to offering streams to its live radio broadcasts, CBC Radio 2 offers a streaming music feature called "Concerts On Demand". Here, over 700 concerts recorded by the CBC are available for streaming through a web browser at the user's convenience.

\section{Bibliothèque nationale de France (http://gallica.bnf.fr/)}

Many libraries are experimenting with delivering their content over the Internet. The Bibliothèque nationale de France offers a rich example with their Gallica interface. The Gallica site contains, among other things, digital reproductions of works in the public domain from the collections of the Bibliothèque nationale de France. Here, via the Internet, a user can search for audio files and listen to library content directly from their web site. 
Examples: social networking and user-generated sites:

Many social networking sites feature streaming music, as do other sites, such as personal blogs, which rely heavily on user-generated content.

\section{1. iLike.com and MySpace (http://www.ilike.com/)}

ILike, a subsidiary of MySpace, is one of the more popular applications available on social networking sites such as Facebook, Google, orkut, hi5 and Bebo. With iLike, users can add their music to their profiles. This music can be searched and played, using the iLike web page and media player. The media player also links to YouTube, so that video streaming can also be a part of the music experience. ILike has 60 million registered users, and according to their web page, "...offers musicians and labels a Universal Artist Dashboard ${ }^{\mathrm{TM}}$ from which to reach fans and manage their presence across many channels: Facebook, iGoogle, iLike.com, iTunes, the iPhone, and more. By leveraging iLike's 'artist-fan graph,' a vast database of connections between consumers and their favorite artists, iLike helps artists reach their fans and cultivate the viral spread of their music."19

\section{Internet Archive (http://www.archive.org/index.php)}

At the Internet Archive users can stream or download music chosen from over 75,000 concert recordings, which feature both independent and major label acts, at no cost. The Archive's mission states, "Live recordings are a part of our culture and might be lost in 100 years if they're not archived. We think music matters and want to preserve it for future generations." ${ }^{20}$ The tracks vary in quality and recordings often originate from fans. All recordings are free to use and are completely legal, as permission from the artists involved has been provided in written form.

Many of these concerts are made available from the Etree community who, according to their wiki, are an "award-winning leader in lossless digital audio distribution on the Internet" and are "a community committed to providing the highest quality live concert recordings in a losslesslycompressed, downloadable format."21

\section{Digital lending}

\section{Overview}

Digital lending is a very new method of accessing music, one that is still taking shape. In digital lending, a user downloads an audio file from their library's web site, and then is able to play the file on a computer or mobile device. There are two features of this method of accessing music that differentiate it from simple downloading: first, digital lending necessarily involves some form of DRM - typically the downloaded file will stop working or expire after a set amount of time (i.e., the "loan" period); second, digital loans function in the same manner as their physical

\footnotetext{
19 “About iLike," iLike, http://www.ilike.com/about (accessed March 16, 2010).

20 "What is The Live Music Archive All About?" Internet Archive, http://www.archive.org/about/faqs.php\#240 (accessed March 16, 2010).

${ }^{21}$ Etree.org community, “Etree Wiki," http://wiki. etree.org/ (accessed March 16, 2010).
} 
counterparts - when one user has downloaded or "borrowed" a particular album, that album is not available for digital loan to a different user until it has been "returned" (i.e., the file has expired on the first user's computer). As Motoko Rich puts it, "The idea is to capture borrowers who might not otherwise use the library, as well as to give existing customers the opportunity to try new formats."22

\section{Advantages and disadvantages}

As with other digital technologies, convenience is a major advantage of digital lending. Users can access music without making a trip to the brick-and-mortar library. Another advantage is that, as with streaming audio technologies, digital lending opens up access to a vast array of content, a selection of music that is usually well beyond the limits of a user's personal collection.

On the negative side, digital lending typically involves downloading additional software which is required to access the digital content and also to transfer files to other devices. This can be timeconsuming and inconvenient. In some cases - for example, for those with limited computer skills - it can prove to be a significant barrier. There are also issues with compatibility. Apple computers and their popular iPod device, for example, are not always supported. Further, digital lending involves an unusual use of digital technology; the phrase itself seems to be a contradiction in terms. Digital files are, by their very nature, more easily reproduced or copied than their physical counterparts; it is much easier to reproduce the electronic files that make up a born-digital album than it is to create another compact disc or vinyl record. Strictly speaking, you cannot really lend a digital file, as you can a book or CD, you can only copy it. Using DRM technology, then, to introduce the limitations of traditional formats (e.g., compact discs) onto new media (e.g., born-digital albums) is, at the very least, counterintuitive.

\section{Examples}

\section{OverDrive (http://www.overdrive.com/)}

OverDrive is an American company that provides the "infrastructure for distributing...digital content" ${ }^{23}$ to public institutions and commercial retailers. They offer "more than 150,000 digital titles including audiobook, eBook, video, and music formats." ${ }^{24}$ When it comes to music, they offer over 5,000 titles in a wide variety of genres. The files are available in the DRM-protected Windows Media Audio (WMA) format, and can be played on a computer, burned to a CD, or transferred to a portable device, if the publisher's license agreement permits. ${ }^{25}$

\section{Barnes and Noble (http://www.barnesandnoble.com/nook/)}

\footnotetext{
22 Motoko Rich, "Libraries and Readers Wade Into Digital Lending," New York Times, October 14, 2009, http://www.nytimes.com/2009/10/15/books/15libraries.html? r=2 (accessed March 16, 2010).

23 “About Us," OverDrive, http://www.overdrive.com/aboutus/ (accessed March 16, 2010).

24 "College Download Library," OverDrive, http://www.overdrive.com/products/cdl/ (accessed March 16, 2010).

25 “Digital Album Downloads," OverDrive, http://www.overdrive.com/resources/mediaformats/music.asp (accessed March 16, 2010).
} 
Barnes and Noble is an American book retailer who, in addition to selling print books through their retail outlets, also sells eBooks through their "nook" eBook reader. They are currently testing a feature whereby customers can "lend" their purchased eBooks to friends; the eBooks can then be read online or with a variety of devices using free software. Similarly to OverDrive, when a particular title has been lent out to a friend, it cannot be used by anyone else, not even the lender themselves. As Barnes and Noble do not currently sell music digitally, the nook does not support the digital lending of music. We have included them here to provide a second example of a company that is experimenting with this new method of distributing digital content.

\section{Conclusion}

The lines between these different models of service are increasingly blurring, and newer sites tend to offer a broad variety of methods for accessing music online. SoundCloud, a relatively new site that allows musicians a high degree of control over how their music is distributed, is a great example. Particular tracks can be streamed on the site or on mobile devices, embedded on other sites, or downloaded, all depending on what distribution methods the musician has enabled.

In the context of a constantly changing digital landscape, we have described three methods for accessing online sound recordings, including downloading, streaming, and digital lending. Furthermore, we have listed relevant examples and have discussed the benefits and drawbacks for each of these methods. We hope that this information will serve as a useful guide to librarians who regularly help their patrons find and discover new music. It may also help with the challenging task of updating collection development policies, as an awareness of new methods of distribution can inform policy decisions. 